35. Гладких В.Г., Денисова О.В. Модель профессионального саморазвития будущего машиностроителя в проектном обучении // Азимут научных исследований: педагогика и психология. 2015. № 4 (13). С. 29-33.

36. Ясаревская О.Н. Проектная деятельность - один из способов развития коммуникативной компетенции студентов (на примере иностранного языка) // XXI век: итоги прошлого и проблемы настоящего плюс. 2015. T. 3. № 6 (28). C. 170-173.

37. Будник С.В. Портфолио как способ оценки исследовательской деятельности подростков в кружковой работе // Азимут научных исследований: педагогика и психология. 2014. № 1. С. 15-17.
38. Брыксина О.Ф., К Калинкина М.В. Дидактика высшей школы: инструментальное обеспечение современных педагогических технологий // Вестник Самарского государственного технического университета. Серия: Психолого-педагогические науки. 2014.№ 4 (24). C. 26-34.

39. Брыксина О.Ф., Тараканова Е.Н. Профессиональные сетевые сообщества как альтернатива формальной системе повышения квалификации педагогов // Актуальные задачи современной науки и образования: теоретические и прикладные аспекты Сборник научных трудов по материалам Международной научнопрактической конференции. 2015. С. 45-46.

\title{
ICT ON-LINE RESOURSES AS A TOOL OF IMPLEMENTING THE FEDERAL STATE EDUCATIONAL STANDARD 44.03.01 PEDAGOGICAL EDUCATION
} (c) 2016

M.A. Voronina, senior lecturer of the Chair of ICT in Education Samara State University of Social Sciences and Education, Samara (Russia)

Abstract. The article considers issues related to the use of the ICT in the modern education and analyzes the requirements of the federal state educational standards of primary, basic and higher education. The attention is focused on the need to develop the ICT competence at all levels of education. The concepts of using information and communication technologies in the classroom as well as the concept of «informatization of education» are analyzed.

A three-level model of the ICT competence of the teachers is described, which is stipulated by the professional teachers' standard. The article analyzes possibilities of interactive lectures supported by the social networks or the use of cloud technologies.

The article proposes the use of the case-study method in the virtual reality as a means of formation of the required competencies and increasing students' motivation. It analyzes the didactic potential of the pedagogical community network as a basis for lifelong learning. The experience of the use of the Internet community as a site of scientific pedagogical research is described. Videoconferences are proposed as a tool of teacher professional development. Google Hangouts application is evaluated as well.

The author draws a conclusion about the necessity for higher school teachers to use modern information technologies in the education process, which make it possible to transfer learning beyond the walls of the educational institution. Such education will comply with the Russian standard of living, and will be acceptable internationally.

Keywords: educational standards, bachelor, higher education, educational outcomes, educational technology, information and communication technologies, competences, innovation.

\section{УДК 37.013 .75}

\section{СРАВНИТЕЛЬНЫЙ АНАЛИЗ ПРЕДСТАВЛЕНИЙ УЧИТЕЛЕЙ САНКТ-ПЕТЕРБУРГА О РОЛИ И СУЩЕСТВЕННЫХ ХАРАКТЕРИСТИКАХ ПЕДАГОГИЧЕСКОЙ ДИАГНОСТИКИ}

(C) 2016

И.Ю. Гутник, кандидат педагогических наук, доцент кафедры педагогики

Российский государственный педагогический университет имени А.И. Гериена, Санкт-Петербург (Россия)

Аннотация. В статье представлен сравнительный анализ представлений учителей города Санкт-Петербурга из репрезентативной выборки и анализ мнений учителей одной из школ Санкт-Петербурга, имеющей многолетний опыт педагогической диагностики направленной на самоопределение ученика. В результате сравнительного анализа были получены выводы об осознании учителями необходимости применения педагогической диагностики в современном образовательном процессе. Было подтверждено понимание учителями важности каждодневного, близкого к интуитивному познанию своих учеников, зафиксировано, что имеющийся опыт сопровождения, базирующегося на педагогической диагностике, делает необходимым знание педагогом проблем и затруднений учеников. Был выявлен существенный дефицит знаний и умений у современного учителя, в области использования различных источников для получения информации об ученике. Было определено недостаточное понимание значимости применения качественных методов диагностики и методов аутентичной диагностики учителями современной школы, а так же недостаточное осознание важности учета мнения коллег и необходимости взаимодействия с ними, значимости коллективного, совместного выстраивания механизма диагностического сопровождения для всего коллектива школы. Была установлена закономерность в том, что обучение теории и практике педагогического диагностирования позволяет снимать многие проблемы в использовании педагогической диагностики - ее трудо- и времязатратность.

Ключевые слова: педагогическая диагностика, педагогическое сопровождение, поддержка, методы педагогической диагностики, рациональная и интуитивная педагогическая диагностика, наблюдение, анкетирование, беседа, портфолио, методы самодиагностики, самоопределение ученика, неформальные тесты. 
Целью данной статьи является анализ данных широкого анкетирования, проведенного в 2015 году в городе Санкт-Петербурге, направленного на изучение представлений учителей Санкт-Петербурга о роли и сущностных характеристиках педагогической диагностики.

Выборка была представлена учителями из разных типов школ разных районов города. Анкетирование было проведено в 30 школах г. Санкт-Петербурга. В целом было опрошено более 300 человек. В опросе участвовали школы из 10 районов города. Включенные в опрос школы находятся в разных районах города как в центральных, так и в так называемых - «спальных», имеют разные статусы - общеобразовательные школы, школы-гимназии, коррекционные школы. Отдельно от всего массива школ обрабатывались данные 197 школы Центрального района, где большинство учителей школы занимаются проблемами педагогической диагностики уже на протяжении нескольких десятков лет, кроме того большая часть из них неоднократно проходили курсы повышения квалификации по проблемам педагогической диагностики и педагогического сопровождения.

Опрос представлял собой анкету, состоящую из 18 вопросов. Блоки анкеты включали изучение различных эффектов и рисков педагогической диагностики в образовательном процессе. Проанализируем ответы учителей только на 8 вопросов, сформулированных для выяснения мнения учителей относительно необходимости применения педагогической диагностики в современной школе, источниках получения информации учителем об учениках, методах, которые учитель использует в своей практике, а так же условиях необходимых для повышения диагностической компетентности учителя.

Первый вопрос был направлен на изучение мнений учителей относительно необходимости применения педагогами педагогической диагностики в современной школе и звучал так: «Оцените по пятибалльной шкале необходимость применения педагогической диагностики в сегодняшней школе т.е. того «Важно ли современному учителю иметь знания о своих учениках, «видеть» ученика в процессе обучения?» Итак, от 1 до 5.Анализ данных свидетельствует о том, что хотя учителя и считают необходимым применение педагогической диагностики - более половины из них выбирает отметку «5», а чуть более $20 \%$ выбирают«4», но и отметки «3», «2» и «1» так же ими выбираются. Анализ ответов учителей 197 школы свидетельствует о том, что абсолютное большинство учителей осознают важность педагогической задачи - «видеть ученика» и учителя данной школы не выбирают отметку ниже «4», понимая значимость данного вида деятельности учителя выше, чем в среднем по городу.

Второй вопрос был сформулирован в целях определения отношения педагогов к необходимости применения педагогической диагностики в современной школе. Вопрос был сформулирован следующим образом: Какие 5 ассоциаций (эпитетов) - отвечающих на вопрос «какая?», возникают у Вас в связи с понятиями, «педагогическая диагностика», «знание об ученике»:

Анализ ответов учителей из общегородской выборки свидетельствует о преобладании положительных эпитетов. Наиболее часто употребляемыми являются эпитеты - нужная, научная, личностно-ориентиро- ваная, объективная. Следующая группа эпитетов так же употребляется значительным числом учителей, но все же меньшим, чем первая группа - трудная, комплексная, своевременная. Это весьма важные характеристики педагогической диагностики, и их немногочисленное упоминание свидетельствует о тенденциях затруднений в ее использовании. Анализ ответов педагогов обозначил следующие проблемы в применении педагогической диагностики в современной школе: недостаточная своевременность в применении, излишняя сложность применяемых методик, малая результативность мер, принимаемых в связи с полученными данными педагогической диагностики; недостаточнокомплексное ее осуществление, т.е применяемость на уровне отдельных учителей, а не на уровне всей школы. Анализ ответов на данный вопрос педагогов 197 школы, в которой уже достаточно давно идет экспериментальная работа по педагогической диагностике показывает другие результаты. Очевидно, что в школе уже найден ответ на вопросы о том, как сделать педагогическую диагностику более объективной, комплексной, менее сложной и даже интересной, так как именно эти характеристики наиболее часто употребляются учителями. Очевидно, что анализ ответов на следующие вопросы позволит нам найти причину такого высокого принятия значимости педагогической диагностики.

Третий вопрос был сформулирован в целях определения того минимума информации, которым учитель должен владеть об ученике. Вопрос был сформулирован так: Что учитель должен знать об ученике? Обработка мнений учителей из выборки представлена на рисунке 1 .

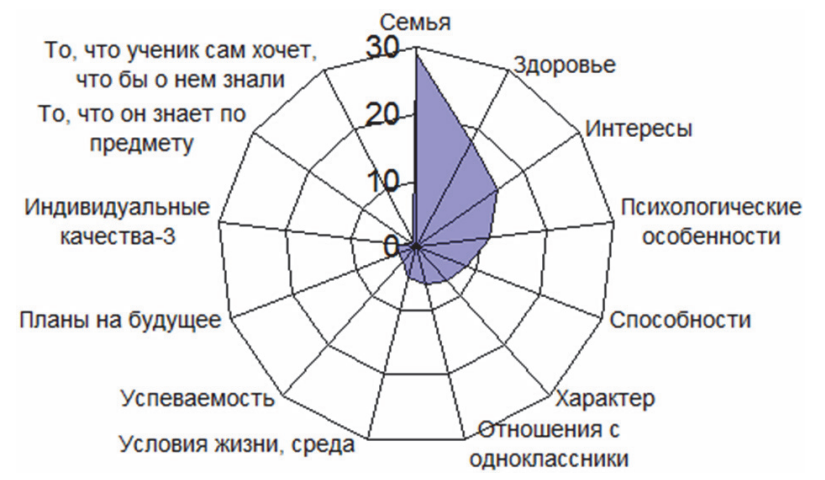

Рисунок 1 - Определение учителями рейтинга наиболее важных знаний об ученике

Интересно, что наиболее важной информацией учителя считают информацию о семье ученика, его здоровье и интересах. Вторую по рейтингу группу источников информации представляют психологические особенности ученика, его способности и характер. Необходимо отметить, что сведения, относящиеся собственно к обучению - знания по предмету, успеваемость, учителя отмечают в качестве необходимых достаточно редко.

Интересно, что мнения учителей 197 школы по данному вопросу, весьма отличаются, поскольку ко всем категориям, полученным в результате опроса мнения учителей из выборки, добавляется параметр - «учитель должен знать проблемы ученика». В школе, в которой осуществляется комплексное, системное сопровождение ученика, учителям важны проблемы их учеников, затруднения имеющиеся у них. 
Четвертый вопрос был сформулирован в открытой форме: Как эти знания можно получить?

Важно было проанализировать значимые, по мнению учителей, источники информации об ученике, не предлагая возможных вариантов, чтобы не ограничивать возможную палитру мнений рамками выбора. Проанализируем мнения учителей из общегородской выборки.

Мы видим, что в качестве ведущих источников знаний об ученике учителя чаще всего указывают процесс общения с самим учеником, его родителями и классным руководителем (одинаково часто указывается опция общение вообще, либо беседа). А наиболее востребованными методами указываются метод наблюдения и анкетирования. Если попытаться выстроить рейтинг всех участников образовательного процесса, с точки зрения того, насколько они важны для получения учителем информации об ученике, то рейтинг будет выглядеть следующим образом: 1.Сам ученик; 2.Его родители; 3.Классный руководитель; 4. Социальный педагог; 5.Медсестра; 6. Одноклассники; 7.Психолог.

Применение конкретных методик педагогической диагностики, как источника знаний об ученике поставлено учителями лишь на 8 место.

Наименее употребляемыми, но все же используемыми, указаны следующие источники знаний об ученике - изучение специальной литературы, беседа с учителями, которые обучали ученика ранее, посещение квартиры ученика. Анализ полученных мнений свидетельствует о том, что для получения информации об ученике учителя весьма редко обращаются к применению специальных методик педагогической диагностики, что может свидетельствовать о том, что они мало осведомлены о них, либо о том, что больше доверяют опыту повседневного общения с учеником. Совсем не указывается мнение коллег и согласованная работа по сопровождению проблем учеников.

Для уточнения наших предположений было необходимо проанализировать ответы учителей 197 школы. Их ответы, свидетельствуют о том, что для них важными источниками информации являются не только использование конкретных методов педагогической диагностики - бесед, анкетирования, портфолио, данных неформальных тестов, но и анализ мнения коллег, данных согласованного мониторинга, направленного на оценку и коррекцию проблем учеников. Анализ ответов педагогов 197 школы свидетельствует, что обучение учителей методам педагогической диагностики повышает арсенал средств, используемых учителем, для познания своих учеников. А так же то, что комплексное и системное сопровождение предполагает включенность в процесс сопровождения не только одного педагога, а совместное, согласованное принятие решений всем педагогическим коллективом.

Пятый вопрос был предложен с целью определения представлений учителей, относительно важности использования конкретных методов педагогической диагностики. Вопрос был сформулирован следующим образом: Наиболее важными способами получения знаний об ученике я считаю... Проставьте рейтинг, в порядке уменьшения значимости от 1 до 9. Итак, 1 - самый важный способ, на ваш взгляд, это:

1.Беседа с учениками и родителями; 2.Наблюдение за деятельностью ученика; 3. Анкета для ученика и ро- дителей;4. Применение конкретных методик; 5.Анализ продуктов деятельности (работы, дневники и проч.); 6.Самодиагностика ученика; 7. Тест (по учебному предмету); 8. Комплексные методы, например «портфолио»;

9. Проверочные работы по предмету (Вопросники).

Анализ ответов учителей свидетельствует, что наиболее важными методами диагностики учителя считают беседу и наблюдение - что, по сути является синонимами повседневного общения, поскольку в «строго-научном» понимании методами не являются, поскольку при их применении никакие научные требования (целеполагания, определение объектов наблюдения, наличия специально-структурированных вопросов, фиксации результатов) не предусматривается и следовательно речь идет не о научном, а о житейском, «наивном», или анекдотическом использовании данных методов [1] - что еще раз поддерживает наше предположение о двухкомпонентном составе педагогической диагностики - интуитивном и рациональном. Собственно научное использование методов имеет следующий рейтинг - 1. Анкета; 2. Анализ продуктов деятельности; 3. Неформальные тесты; 4. Портфолио.

Применение конкретных методик диагностики находится на 4 месте, что вызывает сомнение, так как в предыдущем вопросе, без предложенного выбора (без рамок) важность применения конкретных методик была поставлена только на 8 место.

Интересно, что методы, относящиеся к собственно аттестации, т.е. так называемой «дидактической диагностике» не занимают такого уж главенствующего положения: анализ продуктов деятельности занимает 5 место, неформальные тесты-7 место по рейтингу, проверочные работы-9 место по рейтингу.

Сравнение ответов учителей города и учителей 197 школы свидетельствует о том, что чаще, чем в учителя из выборки, учителя школы 197 выделяют значимость самодиагностики ученика, анкетирования, беседы, тестирований по учебному предмету, анализу работ учеников, наблюдению. Меньше, чем в среднем по городу принимают значимость метода проверочных работ в форме вопросов. Данный рейтинг свидетельствует о высокой компетентности учителей 197 школы в вопросах педагогической диагностики, а так же то, что существует понимание значимости аутентичной диагностики ученика и понимание значимости оценки качества знаний не просто при помощи вопросно-ответной формы, а и неформальными тестами, составленными учителем, для нужд собственной педагогической деятельности.

Шестой вопрос был предложен учителям с целью их самодиагностики относительно владения ими конкретными методами педагогической диагностики. На рисунке 2 представлены результаты обработки мнений учителей относительно своего умения работать с методами педагогической диагностики.

Анализ ответов учителей из выборки, свидетельствует о том, что лучше всего учителя умеют: составлять вопросы для проверочных работ и проводить наблюдение, считают, что умеют анализировать продукты деятельности (работы, дневники и проч.). Хуже всего обстоит ситуация с умением использовать качественные и аутентичные методики педагогической диагностики. Анализ мнений учителей 197 школы свиде- 
тельствует, что ситуация лучше, но в целом тенденция превалирования естественнонаучных методов пока сохраняется.

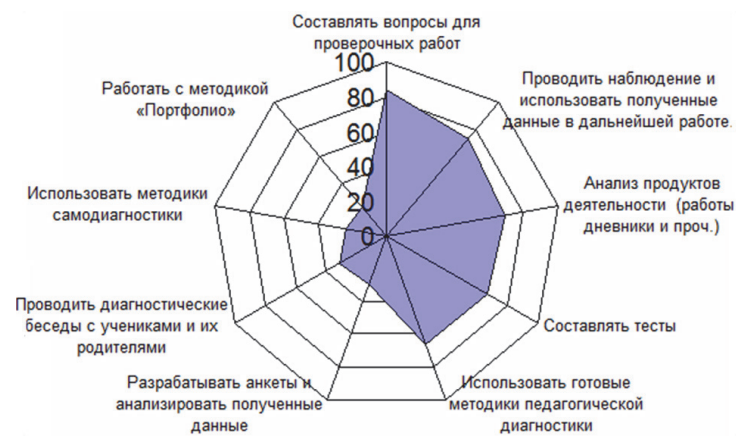

Рисунок 2 - Самооценка учителями своего умения работать с методами педагогической диагностики

Седьмой вопрос был сформулирован с целью поиска ответа на вопрос: какие методы учителя не только умеют использовать, но и действительно используют в своей работе? Анализ ответов учителей показывает, что тенденция выбора предпочтений сохраняется так же как и в предыдущем вопросе. Учителя чаще всего указывают, что оценивают качество знаний при помощи обычных работ в форме вопросов, а не тестов, либо задач, а так же наблюдают и анализируют продукты деятельности. Реже они используют готовые методики педагогической диагностики и составляют тесты. Еще реже они разрабатывают анкеты и беседуют с учениками. Совсем редко они обращаются к аутентичным источникам информации и качественным методам педагогической диагностики, таким, как портфолио.

Сравнение мнений учителей из выборки и мнений учителей 197 школы представлено на рисунке 3.

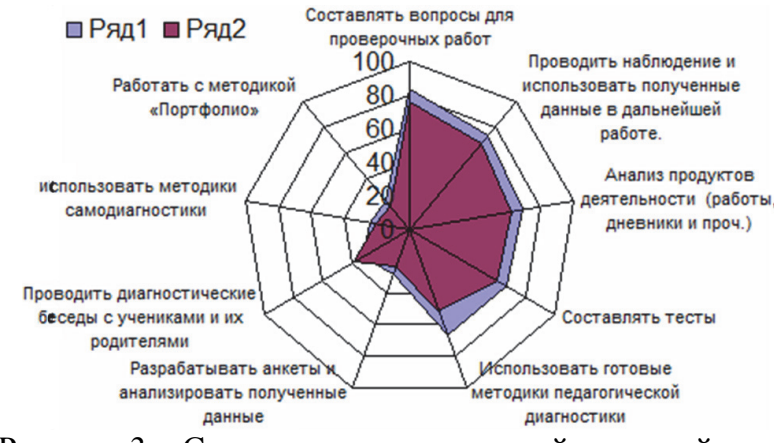

Рисунок 3 - Сравнение представлений учителей школ относительно тех методов, которые они

умеют применять и действительно применяют (ряд 1 - умею; ряд 2 - делаю)

Анализ мнений учителей 197 школы показывает, что тенденция, характерная для ответов совокупной выборки сохраняется, хотя частота применения данных методов выше, чем по городу.

Заканчивая рассмотрение вопроса о применении методов педагогической диагностики необходимо рассмотреть представление педагогов о значимости методов педагогической диагностик комплексно. Соотнеся ответы с 4 по 7 вопрос, условно назвав данное соотнесение: «Есть-Надо-Умею-Применяю» можно получить следующие выводы. В таблице 1 представлено место по рейтингу для каждого из методов педагогической диагностики.

Соотношение полученных данных свидетельствует о том, что наиболее сложная ситуация в образователь- ной практике складывается с методом беседы [2]. Так, указывая, что основную информацию учителя получают именно из общения с учениками и их родителями, учителя пишут, что беседы они проводить практически не умеют и возможностей такого метода не используют. Как объяснить данный парадокс? Причина очевидно в том, что под беседой учителями понимается - воспитательная, назидательная беседа, как специальноорганизованная процедура, а более значимой учителя считают повседневную коммуникацию, где собственно беседы как таковой, по их мнению, и не видно.

Таблица 1 - Соотнесение представлений учителей о необходимости применения методов педагогической диагностики, наличия умения их применять, и факта их реального применения в практике

\begin{tabular}{|l|c|c|c|c|}
\hline & Есть & Надо & Умею & Применяю \\
\hline Беседа & 1 & 1 & 7 & 6 \\
\hline Наблюдение & 2 & 2 & 2 & 2 \\
\hline Анкета & 3 & 3 & 6 & 6 \\
\hline $\begin{array}{l}\text { Конкретные мето- } \\
\text { дики }\end{array}$ & 8 & 4 & 5 & 5 \\
\hline $\begin{array}{l}\text { Анализ продуктов } \\
\text { деятельности (днев- } \\
\text { ники, сочинения) }\end{array}$ & 0 & 5 & 3 & 3 \\
\hline Портфолио & 0 & 8 & 9 & 9 \\
\hline
\end{tabular}

Значение метода наблюдения [3] оценивается учителями весьма адекватно. Высоко осознается его значимость, и так же часто он применяется. Но необходимо помнить, что мы опять же сталкиваемся не с научным методом наблюдения, а с так называемым «наивным», анекдотическим наблюдением.

Что касается проблемы использования метода анкетирования [4] можно увидеть, что значимость данного метода учителя оценивают очень высоко, но при этом указывают, что не умеют им пользоваться или пользуются весьма редко.

Удивительным кажется и явное несоответствие в том, что если подавляющее большинство учителей считает самого ученика - ведущим источником информации о себе, то методики самодиагностики ученика помещены ими же лишь на 6 место. В данном случае можно предположить дефицит знаний у учителей относительно методик самодиагностики для ученика.

Что касается проблемы использования готовых методик педагогической диагностики, то мы видим, что если их не предлагать как инструмент получения информации об ученике, то сами учителя про них и не вспоминают. В случае если их предложить в числе прочих, то их помещают в середину рейтинга. А вот указывают, что используют готовые методики диагностики только 20\% учителей. Налицо недостаточность знаний о широкой палитре существующих методик педагогической диагностики.

Метод портфолио, без напоминания о нем, не указывался учителями вообще (в открытом 4 вопросе), а в случае с выбором из имеющегося (в 5 вопросе), был поставлен на предпоследнее место, что свидетельствует о недостаточном осознании важности данной методики, либо его осознанном неприятии, в случае негативного опыта его использования [5].

Восьмой вопрос был предложен в целях поиска дополнительных ресурсов, которые способствовали бы, 
по мнению учителей, более широкому применению педагогической диагностики. Вопрос был сформулирован следующим образом: Почему педагогическая диагностика используется российскими учителями меньше, чем это принято в большинстве европейских стран? В чем причина? Что лично Вам необходимо для того, чтобы Bы постоянно использовали педагогическую диагностику в школе?

1) Больше знаний по педагогической диагностике; 2) Больше умений по педагогической диагностике; 3) Больше доступных и эффективных методик; 4) Больше времени на данный вид работы, за счет включения данных затрат в нагрузку; 5) Большая зарплата; 6) Меньшее количество учеников в классе.

Анализ мнений учителей по данному вопросу представлен на рисунке 4.

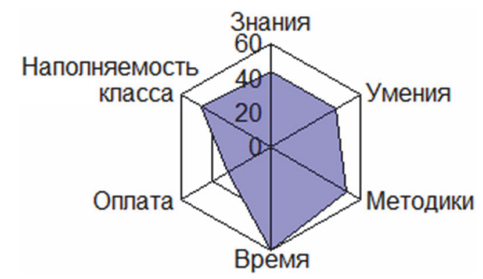

Рисунок 4 - Представления учителей школ относительно недостающих условий

для полноценного применения педагогической диагностики в образовательном процессе

На данной диаграмме можно четко проследить предпочтения в ответах учителей относительно условий необходимых для более широкого применения педагогической диагностики в школе. Очевидно, что по мнению большинства учителей им не хватает времени на применение педагогической диагностики, существует нехватка диагностических знаний и умений в их диагностической компетентности, желательно так же изменение наполняемости класса и осуществление дополнительного финансирования за дополнительную нагрузку по осуществлению педагогической диагностики.

Анализ мнений учителей 197 школы свидетельствует о том, что, по их мнению, частоту применения педагогической диагностики может увеличить наличие у них больших знаний и умений по педагогической диагностике, что свидетельствует об их понимании необходимости постоянного совершенствования своей диагностической компетентности.

Обобщая полученные в результате опроса данные можно сделать выводы о том, что:

1.Анализ мнений учителей подтверждает актуальность, значимость, осознанность необходимости применения педагогической диагностики в современном образовательном процессе.

2. Подтверждается осознание учителями важности каждодневного, близкого к интуитивному познанию своих учеников [6].

3. Зафиксировано, что имеющийся опыт сопровождения, базирующегося на педагогической диагностике, делает необходимым знание педагогом проблем и затруднений своих учеников.

4. Выявлен существенный дефицит знаний и умений у современного учителя, в его умении использовать различные источники для получения информации об ученике.

5. Определено недостаточное понимание значимости применения качественных методов диагностики и методов аутентичной диагностики, учителями современной школы.

6. Определено недостаточное осознание важности учета мнения коллег и необходимости взаимодействия с ними, значимости коллективного, совместного выстраивания механизма диагностического сопровождения для всего коллектива школы.

7. Установлена закономерность в том, что обучение теории и практике педагогического диагностирования позволяет снимать многие проблемы в использовании педагогической диагностики - ее трудо- и времязатратность.

Выявленные проблемы, безусловно, должны находить свое отражение в подготовке студентов - будущих учителей [7] и в повышении квалификации учителей нынешних [8]. Необходимо уделять больше внимания вопросам обучения о путях и формах реализации индивидуального и коллективного сопровождения и поддержки учеников [9], необходимых для всех направлений самоопределения ученика - личностного [10], социального [11], предметного и профессионального [12].

\section{СПИСОК ЛИТЕРАТУРЫ:}

1. Львова Ю.Л. Творческая лаборатория учителя: Из опыта работы. М., 1980. С. 112.

2. Пичугин А.В., Смирнов В.Б. Беседа: разновидность интервью или самостоятельный жанр // Вестник Волгоградского государственного университета. 2005. № 4. С. $118-121$.

3. Рубинштейн С.Л. Проблемы общей психологии. М., 1973. С. 114.

4. Ядов В.А. Социологическое исследование: методология, программа, методы. М., 1972. С. 74-75.

5. Даутова О.Б. Самоопределение личности школьника в профильном обучении: учебно-методическое пособие / под ред. А.П. Тряпицыной. СПб.: КАРО, 2006. С. 234-235.

6. Барбитова А.Д. Интуитивный подход в педагогической деятельности // Вектор науки Тольяттинского государственного университета. 2010. № 1 (11). С. 165 169.

7. Тряпицына А.П. Проектирование процесса изучения дисциплины «Педагогика» в контексте развития профессиональной компетентности студентов // Известия Российской Академии образования, вып. 4(32), 2014. Изд-во ОАНО ВО «Московский психологосоциальный университет». С. 17-26

8. Гутник И.Ю. Акулова О.В., Батракова И.С., Гладкая И.В. Исследование процесса становления профессиональной компетентности будущих педагогов. СПб.: Из-во РГПУ им.А.И. Герцена, 2011. С. 195.

9. Касицына Н., Михайлова Н., Юсфин С. Педагогика поддержки. СПб., 2005. 295 с.

10. Антипова Ю.А., Валяева Е.Б. и др. Сопровождение личностного самоопределения младшего школьника: учебно-методический комплекс / под. ред. И.Ю. Гутник. СПб.: Лема, 2015. 161 с.

11. Алесюк О.С., Балуевский А.Ю. и др. Навигатор индивидуального образовательного маршрута ученика: Учебно-методические рекомендации. Из практики ОЭР. СПб.: Своё издательство, 2013. 80 с.

12. Гембель Т.П. Процесс-фолио предметного и профессионального самоопределения учащихся. Учебно-методические рекомендации для учителей / под. ред. И.Ю. Гутник. СПб.: Свое издательство, 2014. 42 с. 


\title{
COMPARATIVE ANALYSIS OF THE VIEWS OF SAINT PETERSBURG TEACHERS ON THE ROLE AND ESSENTIAL CHARACTERISTICS OF PEDAGOGICAL DIAGNOSTICS
}

(C) 2016

\author{
I.Yu. Gutnik, candidate of pedagogical sciences, associate professor of Chair of Pedagogy \\ Herzen State Pedagogical University of Russia, Saint Petersburg (Russia)
}

\begin{abstract}
The article presents a comparative analysis of the perceptions of St. Petersburg teachers from a representative sampling and analysis of opinions of teachers one of the schools of St. Petersburg that has a lot of experience in pedagogical diagnostics aimed at the students' self-determination. As a result of the comparative analysis it was ascertained that the teachers are aware of the necessity of pedagogical diagnostics in modern educational process. Our research confirmed the teachers' awareness of the importance of daily, close to the intuitive knowledge of their students and that the existing experience of student support based on educational diagnostics, makes it necessary for the teacher to know the students' problems and difficulties. Teachers lack knowledge and skills as far as the use of different sources for information about the student is concerned. Teachers do not quite understand the importance of applying qualitative and authentic methods of diagnosis, as well as the importance of taking into account the opinions of the colleagues and need to interact with them, the significance of collectively, jointly developing a mechanism and diagnostic support for all school staff. It is shown that the training in the theory and practice of pedagogical diagnosis allows teachers to eliminate many problems of pedagogical diagnostics, namely, its being labor- and time-consuming.

Keywords: pedagogical diagnostics, pedagogical support, support, methods of pedagogical diagnostics, pedagogical rational and intuitive diagnosis, observation, questionnaire, interview, portfolio, methods of diagnosis, student selfdetermination, informal tests.
\end{abstract}

\section{УДК 372.8}

\section{СОВЕРШЕНСТВОВАНИЕ ФОРМИРОВАНИЯ ЭКОНОМЕТРИЧЕСКИХ ЗНАНИЙ ПРИ ОБУЧЕНИИ БАКАЛАВРОВ - ПЕДАГОГОВ ЭКОНОМИЧЕСКОГО ПРОФИЛЯ}

(C) 2016

Ю.В. Зелепухин, кандидат технических наук, доцент, заведующий кафедрой экономического образования

О.Ю. Цыбина, старший преподаватель кафедры экономического образования

Самарский государственный соииально-педагогический университет, Самара (Россия)

Аннотащия. Концепция модернизации российского образования ставит вопрос о необходимости введения профильного обучения для совершенствования и развития школьной системы образования. Актуально то, что для реализации идей усовершенствования образования первоочередной задачей является наличие высококвалифированных учителей для работы в профильных классах. Одним из самых сложных является обучение студентов для работы в классах социально-экономического профиля. Будущие учителя, обучающиеся по профилю «Экономика», должны использовать экономико-математические и эконометрические методы при решении социальноэкономических вопросов, знать достижения мировой экономической мысли, обладать общей экономикоматематической культурой. Для достижения этих целей в вузах преподаётся эконометрика. Являясь междисциплинарной наукой, она базируется на математических и экономических знаниях. За последние 40 лет произошло стремительное развитие эконометрики как научной дисциплины. Как свидетельство международного признания и значимости выступило награждение нобелевскими премиями в области экономики за выдающиеся исследования в области эконометрики таким учёным, как Рагнар Фриш и Ян Тинберген, Джеймс Хекман и Дэниел Макфадден. Стоит отметить, что всё больше эконометрические методы применяются в различных публикациях и исследованиях. В эконометрику глубоко проникают новейшие информационные технологии и математические методы. Изучение эконометрики студентами-педагогами экономического профиля положительно влияет на познание мира и усвоение различных знаний, так как математический язык считается универсальным и тот, кто умеет им пользоваться, успешно сможет применить свои знания в различных областях науки и производства. Статья посвящена вопросам совершенствования формирования эконометрических знаний при обучении бакалавров-педагогов экономического профиля.

Ключевые слова: концепция модернизации российского образования, эконометрические знания, экономическое мышление, экономико-математические и эконометрические методы, бакалавры-педагоги экономического профиля, учебный план, основная образовательная программа, федеральный государственный образовательный стандарт высшего профессионального образования, направление подготовки «Педагогическое образование», профессиональные компетенции, активные методы обучения, компетентностный подход к образованию.

Результатом присоединения России к Болонскому процессу стало то, что многие общеуниверситетские дисциплины подготовки студентов стали преподавать студентам педагогических вузов. Популярным стало направление эконометрическое моделирование, объединяющее математические методы, которые основываются на экономической теории, экономической ста- тистике, математико-статистическом инструментарии, с целью придания конкретных количественных выражений общим закономерностям $[1,2,3,4,5,6,7]$.

Основной отличительной особенностью Болонского процесса можно назвать процесс трансформации знаний, умений и навыков в некие компетенции, которые буду необходимы выпускнику впоследствии в профес- 